\title{
Perbedaan Penerimaan Diri Ibu yang Memiliki Anak Tunagrahita ditinjau dari Tingkat Pendidikan di SLB-E PTP Medan
}

\section{The Different Self Acceptance Mother with}

\author{
Eryanti Novita * \\ Universitas Medan Area , Indonesia \\ *Corresponding author: E-mail: titinovita1@gmail.com
}

\begin{abstract}
Abstrak
Penelitian ini bertujuan untuk melihat perbedaan penerimaan diri ibu yang memiliki anak tunagrahita ditinjau dari tingkat pendidikan, dimana subjek penelitian adalah ibu dari anak tunagrahita di SLB-E PTP yang berjumlah 60 orang. Dimana 30 ibu berpendidikan SMA, dan 30 ibu berpendidikan Sarjana.Sejalan dengan pembahasan yang ada dalam landasan teori, maka hipotesis yang diajukan dalam penelitian ini berbunyi: Ada perbedaan penerimaan diri ibu yang memiliki anak tunagrahita ditinjau dari tingkat pendidikan Dalam $t$-test. upaya membuktikan hipotesis tersebut, digunakan metode analisis data t dimana berdasarkan pengolahan data, diperoleh hasil-hasil sebagai berikut: a). terdapat perbedaan penerimaan diri antara ibu dengan tingkat pendidikan sarjana danibu dengan tingkat pendidikan SMA yang signifikan dengan signifikan $p=0.000<0,050$. Artinya adanya perbedaan penerimaan diri antara ibu dengan tingkat pendidikan sarjana dan ibu dengan tingkat pendidikan SMA, dinyatakan diterima. b). Secara umum hasil penelitian ini menyatakan bahwa penerimaan diri ibu dengan tingkat pendidikan Sarjana lebih tinggi dibandingkan Penerimaan diri ibu dengan tingkat pendidikan SMA. Penerimaan diri ibu dengan tingkat pendidikan sarjana mean empiriknya adalah 155.10 dan Penerimaan diri ibu dengan tingkat pendidikan SMA mean empiriknya adalah 138.53, sedangkan nilai rata-rata hipotetiknya sebesar $=127.5$
\end{abstract}

Kata Kunci: Penerimaan Diri, Tuna Grahita, Tingkat Pendidikan

\begin{abstract}
This study aims to see differences in self-acceptance of mothers who have children with mental retardation from the level of education, where the subject of research is the mother of child tunagrahita in SLB-E PTP which amounts to 60 people. Where 30 high school-educated mothers, and 30 mothers educated undergraduate. In line with the existing discussion in the theoretical basis, the hypothesis proposed in this study reads: There is a difference in self-acceptance of mothers who have children tunagrahita reviewed from the level of education In t-test. efforts to prove the hypothesis, used data analysis method $t$ where based on data processing, obtained the results as follows: a). there is a difference of self-acceptance between mothers with undergraduate and baccalaureate education level with significant high school level with significant $p=0.000<0,050$. This means that there is a difference of self-acceptance between mothers with undergraduate education level and mothers with high school education level, declared accepted. b). In general, the results of this study states that the self-acceptance of mothers with the level of education Bachelor is higher than self-acceptance of mothers with high school education level. The mother's self-acceptance with the level of undergraduate education of the empirical mean is 155.10 and the self-acceptance of the mother with the SMA level of the empirical mean is 138.53, while the mean hypothetical value is $=127.5$
\end{abstract}

Keywords: Coping Stress; Cancer Patient; Man; Woman

How to Cite: Novita, E. 2017. Perbedaan Penerimaan Diri Ibu yang Memiliki Anak Tunagrahita Ditinjau dari Tingkat Pendidikan di SLB-E PTP Medan. Jurnal Diversita, 3 (1):67-74 


\section{PENDAHULUAN}

Pemahaman masyarakat umum mengenai anak berkebutuhan khusus masih sangat minim, kebanyakan mereka menganggap bahwa anak berkebutuhan khusus merupakan anak yang tidak memiliki kemampuan apapun. Salah satu dari mereka adalah anak tunagarahita. Anak tunagrahita adalah kondisi anak yang kecerdasannya jauh dibawah ratarata yang ditandai oleh keterbatasan intelegensi dan ketidak cakapan dalam berinteraksi sosial. Anak tuna grahita atau dikenal juga dengan istilah keterbelakangan mental karena keterbatasan kecerdasannya sukar untuk mengkuti program pendidikan disekolah biasa secara klasikal.

Frieda (2009) mengemukakan bahwa anak yang berkebutuhan khusus adalah anak yang mengalami keterbatasan fisik dan mental seperti sulit mendengar/ tuli, kelainan bicara, kelainan dalam penglihatan, gangguan emosi yang serius dan kesulitan belajar. Salah satu anak berkebutuhan khusus yakni anak tunagrahita. Munzayanah (2004) mengatakan anak cacat mental atau anak tunagrahita adalah anak yang mengalami gangguan dalam perkembangan daya pikir serta kepribadiannya sehingga mereka tidak mampu hidup dengan kekuatannya sendiri didalam masyarakat meskipun dengan cara hidup yang sederhana.

Tidak semua orang tua yang memiliki anak tunagrahita memiliki sikap yang wajar. Anak tunagrahita biasanya suka diperlakukan berlebihan, segala keinginanya dipenuhi, pekerjaanya selalu dibantu, atau ada juga sebaliknya, anak dibiarkan begitu saja berada diluar jangkauan orang tua atau dikurung karena merasa malu oleh tetangga. Ada dua sikap yang bertentangan yang sering dilakukan orang tua kepada anaknya yang pernah disadari oleh orangtua itu sendiri yaitu orang tua sering memperlakukan anak tunagrahita dengan sikap over protection atau sebaliknya bersikap menolak kehadiran anak tersebut (Sartinah, 2002). Ada orang tua yang menerimanya sebagai takdir dan menerima keadaan anaknya dengan sabar sehingga berusaha mengoptimalkan kemampuan yang dimiliki oleh anaknya. Namun sebagian orang tua merasa terpukul dengan keadaan anaknya, selain itu orang tua juga merasa malu, rendah diri, merasa bersalah dan tidak bisa menerima kenyataan saat mengetahui anaknya tunagrahita. Terutama seorang Ibu yang melahirkan anak tersebut akan lebih memiliki perasaan terpukul.

Purwandari (2005) menyatakan anak tunagrahita memerlukan perhatian khusus dari orang tua berupa membantu anak tunagrahita agar timbul sikap percaya diri, mandiri, menjadi manusia yang produktif, memiliki kehidupan yang layak, dan aman terlindungi serta bahagia lahir dan batin. Penerimaan orang tua merupakan suatu efek psikologis dan perilaku dari orang tua pada anaknya seperti rasa sayang, kelekatan, kepedulian, dukungan pengasuhan dimana orang tua tersebut bisa merasakan dan mengekspresikan rasa sayang kepada anaknya menurut (Hurlock, 2001). Purwandari (2005) menambahkan bahwa lingkungan dan orang tua biasanya kurang memahami kondisi anak tunagrahita yakni menyamakannya dengan anak normal. Orang tua dan lingkungan diharapkan memahami anak tunagrahita dengan tidak 
terpaku pada tugas-tugas perkembangan. Tugas-tugas perkembangan hanya dipakai sebagai pemicu, orangtualah yang membantu seoptimal mungkin agar anak dapat melampaui setiap periode perkembangan dengan alami sesuai keterbatasannya.

Orang tua yang memiliki anak tunagrahita memiliki beban berat dalam mengurus anak, karena anak tunagrahita memiliki kelemahan-kelemahan tersendiri dan harus mendapat perhatian lebih yang berbeda dengan anak normal lainnya. Selain itu, beban lain yang dirasakan orang tua yang memiliki anak tunagrahita biasanya berasal dari lingkungan sosial. "Orang awam" yang tidak memiliki pengetahuan mengenai anak tunagrahita akan memandang anak tunagrahita sebagai anak yang tidak normal dan acap kali disepelekan. Penilaian-penilaian dari lingkungan ini akan mempengaruhi kejiwaan orang tua anak tersebut. Perasaan dan tingkah laku orang tua yang memiliki anak tunagrahita yaitu pertama, perasaan kehilangan kepercayaan diri karena mempunyai anak yang tidak normal. Orang tua menjadi cepat marah dan menyebabkan tingkah laku agresif. Pada permulaan, orang tua mampu menyesuaikan diri namun akan terganggu lagi saat menghadapi peristiwa seperti anak memasuki usia sekolah, meninggalkan sekolah, dan orang tua semakin tua sehingga tidak mampu lagi memelihara anaknya. Kedua, kehilangan kepercayaan diri dalam mengasuh anaknya. Orang tua merasa ada yang tidak beres dengan urusan keturunan, sehingga mendorong perasaan depresi dan kurang mampu mengasuh anaknya. Ketiga, Ada perasaan kehilangan kepercayaan diri untuk bergaul. Orang tua bingung dan malu, sehingga orang tua kurang suka bergaul dengan tetangga dan lebih senang menyendiri (Somantri, 2006)

Menurut hasil Survey Sosial Ekonomi Nasional (Susenas) yang dilaksanakan Biro Pusat Statistik (BPS) tahun 2012, jumlah penyandang disabilitas di Indonesia sebanyak 6.008.661 orang. Dari jumlah tersebut sekitar $\quad 1.780 .200$ orang adalah penyandang disabilitas netra, 472.855 orang penyandang disabilitas rungu wicara,402.817 orang penyandang disabilitas grahita/intelektual, 616.387 orang penyandang disabilitas tubuh. Kondisi ini diperkirakan akan terus mengalami peningkatan, seiring dengan meningkatnya pertumbuhan penduduk dan berbagai faktor lainnya yang memicu peningkatan jumlah penyandang cacat. Ada beberapa sikap yang banyak dilihat pada keluarga yang mempunyai anak tidak normal antara lain : acceptence, overprotectiveness, perfectionist dan rejection. Dalam penerimaan anak juga perilaku ibu berbeda beda, salah satu faktor nya yaitu pendidikan, dimana pendidikan orang tua merupakan pondasi dikemudian hari. Semakin baik pendidikan orang tua maka peluang orientasi, peluang ketahanan dan kekebalan tubuh juga semakin baik. (Wardhani, 2012). Subjek penelitian ini adalah anak penyandang tunagrahita di SLB-E Negeri PTP Medan.

Pemahaman masyarakat umum mengenai anak berkebutuhan khusus masih sangat minim, kebanyakan mereka menganggap bahwa anak berkebutuhan khusus merupakan anak yang tidak memiliki kemampuan apapun. Salah satu dari mereka adalah anak tunagarahita. 
Anak tunagrahita adalah kondisi anak yang kecerdasannya jauh dibawah ratarata yang ditandai oleh keterbatasan intelegensi dan ketidakcakapan dalam interaksi social. Anak tunagrahita atau dikenal juga dengan istilah keterbelakang mental karena keterbatasan kecerdasannya sukar untuk mengkuti program pendidikan disekolah biasa secara klasikal. Anak cacat mental atau anak tuna grahita adalah anak yang mengalami gangguan dalam perkembangan daya pikir serta seluruh kepribadiannya sehingga mereka tidak mampu hidup dengan kekuatan sendiri didalam masyarakat meskipun dengan cara hidup yang sederhana. Terdapat dua sikap yang bertentangan yang sering dilakukan orang tua kepada anaknya yang pernah disadari oleh orang tua itu sendiri.

Orang tua sering memperlakukan anak tunagrahita dengan sikap over protection atau sebaliknya bersikap menolak kehadiran anak tersebut. Ada orang tua yang menerimanya sebagai takdir dan menerima keadaan anaknya dengan sabar sehingga berusaha mengoptimalkan kemampuan yang dimiliki oleh anaknya. Namun sebagian orang tua merasa terpukul dengan keadaan anaknya, selain itu orang tua juga merasa malu, rendah diri, merasa bersalah dan tidak bisa menerima kenyataan saat mengetahui anaknya tuna grahita. Penerimaan orang tua yaitu suatu efek psikologis dan perilaku dari orang tua pada anaknya seperti rasa sayang, kelekatan, kepedulian, dukungan pengasuhan dimana orang tua tersebut bisa merasakan dan mengekspresikan rasa sayang kepada anaknya. Orang tua terutama ibu yang memiliki anak tunagrahita memiliki beban berat dalam mengurus anak, karena anak tunagrahita memiliki kelemahan-kelemahan tersendiri dan harus mendapat perhatian lebih yang berbeda dengan anak normal lainnya.

Agar penelitian ini dapat dilakukan lebih fokus, sempurna, dan mendalam maka penulis merasa permasalahan ini perlu dibatasi variabelnya. Oleh sebab itu, penulis membatasi diri hanya membahas penerimaan ibu yang memiliki anak tunagrahita, yang berpendidikan SMA atau Sarjanadi SLB-E Negeri PTP Medan. Sesuai dengan identifikasi masalah diatas maka peneliti mengajukan rumusan masalah penelitian ini dalam bentuk pertanyaan "apakah ada perbedaan penerimaan ibu yang memiliki anak tunagrahita ditinjau dari tingkat pendidikan?. Tujuan Penelitian ini adalah Untuk mengetahui "apakah ada perbedaan penerimaan diri ibu yang memiliki anak tunagrahita ditinjau dari tingkat pendidikan".

\section{METODE PENELITIAN}

Jenis penelitian ini termasuk ke dalam penelitian kuantitatif. Hal ini disebabkan karena data-data yang diperoleh dalam penelitian ini berupa angka angka, sehingga untuk mengetahui valid atau tidaknya data-data tersebut, perlu diuji dengan menggunakan analisis statistika. Dalam penelitian ini, penulis ingin mencari Perbedaan Penerimaan Diri Ibu yang Memiliki Anak Tunagrahita Ditinjau dari Tingkat Pendidikan di SLB-E Negeri PTP Medan. Variabel Bebas (X) adalah Tingkat Pendidikan, dan Variabel Tergantung $(\mathrm{Y})$ adalah Penerimaan Diri Ibu. Populasi dalam penelitian ini adalah ibu dari anak penyandang tunagrahita di 
SLB-E Negeri PTP Medan dengan populasi 102 orang. Sedangkan sampel dalam penelitian ini adalah Jumlah ibu yang berpendidikan SMA, 40 orang. Ibu berpendidikan sarjana, 30 orang. Ibu yang berpendidikan SMP, 28 orang. Dan ibu yang tidak memasuki jenjang pendidikan, 4 orang. Sampel yang sesuai karakteristik adalah 60 orang, yaitu 30 ibu yang berpendidikan SMA, dan 30 ibu yang berpendidikan sarjana.

Pada penelitian ini metode pengumpulan datanya menggunakan beberapa pernyataan yang dituang dalam bentuk skala psikologis, yang langsung diberikan kepada seluruh orang tua dari anak penyandang tunagrahita. Cara pengumpulan data adalah dengan menyebarkan skala kepada sampel yang dikenakan. Skala yang di sebar berisi daftar pertanyaan yang telah disiapkan dan disusun sedemikian rupa. Skala yang diberikan adalah skala penerimaan diri ibu. Skala Penerimaan diri Ibu dapat diukur dari aspek menurut Jhonson dan Medinnus (2000) yaitu menghargai anak sebagai individu, menilai anaknya sebagai diri yang unik, mengenal kebutuhan anak, dan mencintai anak tanpa syarat.

Pengukuran dilakukan dengan menggunakan Skala Likert dengan penilaian yang terdiri dari 4 jawaban yaitu: "SS (Sangat Setuju)", jawaban "S (Setuju)", "TS (Tidak Setuju)" dan "STS (Sangat Tidak Setuju)".

Metode pengumpulan data dalam penelitian ini dilakukan dengan menggunakan metode kuantitatif. Metode pengumpulan data kuantitatif dengan menggunakan skala. Skala mempunyai keuntungan sebagai pengumpulan data yang baik.
Maka teknik analisis data yang digunakan dalam penelitian ini adalah Ttest, dan dimana analisis t-test digunakan untuk menganalisis dua kelompok yang berbeda mengenai satu variabel dengan jumlah sampel yang masing masing berjumlah sama (Hadi, 2004). Dalam penelitian ini dua kelompok dimaksud adalah Ibu dari anak tuna grahita yang berpendidikan SMA dan ibu dari anak tuna grahita yang berpendidikan Sarjana.

\section{HASIL DAN PEMBAHASAN}

Berdasarkan uji coba alat ukur diketahui skala penerimaan diri dari 60 aitem terdapat 9 aitem yang gugur memiliki skor Corrected Item-Total Correlation (indeks daya beda $\mathrm{r}_{\mathrm{xy}}$ ) $<0,3$; yaitu aitem nomor $9,18,22,26,31,50,54$, 56, 60. Dan 51 aitem lainnya valid memiliki skor Corrected Item-Total Correlation (indeks daya beda $\mathrm{r}_{\mathrm{xy}}$ ) $>0,3$; dengan skor bergerak dari rbt $=0.301$ sampai $\mathrm{rbt}=0.627$, dengan skor reliabilitas (keandalan) Cronbach Alpha 0.934 .

Penelitian dilaksanakan pada tanggal 15 April 2017 kepada 60 ibu yang memiliki anak tunagrahita, dimana $60 \mathrm{ibu}$ tersebut adalah 30 dari ibu anak tunagrahita yang berpendidikan terakhir SMA dan $30 \mathrm{ibu}$ anak tunagrahita yang berpendidikan terakhir Sarjana. Pengambilan data dilakukan dengan cara penyebaran angket yang dimulai dengan membagikan angket kepada setiap ibu anak tunagrahita yang sedang duduk di taman yang sedang menunggu anak nya selesai. Sebelum membagikan angket, peneliti memperkenalkan diri dan memberikan informasi mengenai maksud dan tujuan peneliti menyebar skala. 
Setelah para ibu memahami akan tata cara mengisi skala, maka penelitilangsung membagikan skala tersebut untuk diisi. Waktu yang diberikan dalam mengisi skala ini tidak dibatasi.

\section{Tabel 1.Rangkuman Hasil Perhitungan} Uji Normalitas Sebaran

\begin{tabular}{|c|c|c|c|c|c||}
\hline Var & RERATA & SB/SD & K-S & P & Ke \\
\hline $\begin{array}{c}\text { Peneri } \\
\text { maan } \\
\text { diri }\end{array}$ & 146.82 & 18.628 & 0.621 & 0.835 & Normal \\
\hline
\end{tabular}

Keterangan :

$\begin{array}{lll}\text { RERATA } & =\text { Nilai rata-rata } \\ \mathrm{K}-\mathrm{S} & =\text { Koefisien } & \\ & \text { Smirnov } \\ \mathrm{SB} & = & \text { Simpangan } \\ & & \text { Deviasi) } \\ & & \\ \mathrm{p} & = & \text { Signifikansi }\end{array}$

Tabel 2.Rangkuman Hasil Perhitungan Uji Homogenitas Varians

\begin{tabular}{|c|c|c|c|c|}
\hline Variabel & Uji & F & Sig & Ket. \\
\hline $\begin{array}{c}\text { Penerimaan } \\
\text { Diri }\end{array}$ & $\begin{array}{c}\text { Levense } \\
\text { Test }\end{array}$ & 0.302 & 0.585 & Homogen \\
\hline
\end{tabular}

Tabel 3. Rangkuman Hasil Analisis T-test

\begin{tabular}{|c|c|c|c|c|}
\hline Sumber & JK & Db & T & Sig \\
\hline Antar A & 57.079 & 58 & 3.821 & 0.000 \\
\hline
\end{tabular}

$\begin{array}{ll}\text { Keterangan : } & \\ \text { Antar A } & \text { : Antar Penerimaan diri } \\ \mathrm{JK} & \text { : Jumlah Kuadrat } \\ \mathrm{Db} & \text { : Derajat Kebebasan } \\ \mathrm{t} & \text { : Koefisien Perbedaan } \\ \mathrm{Sig} & \text { : Signifikansi }\end{array}$

Tabel 4. Hasil Perhitungan Nilai RataRata Hipotetik dan Empirik

\begin{tabular}{|c|l|c|c|l|}
\hline $\begin{array}{c}\text { Variabel } \\
\text { Penerimaan } \\
\text { Diri }\end{array}$ & \multirow{2}{*}{$\begin{array}{l}S B \\
S D\end{array}$} & \multicolumn{2}{|c|}{$\begin{array}{c}\text { Nilai Rata- } \\
\text { Rata }\end{array}$} & \multirow{2}{*}{ Ket } \\
\cline { 3 - 4 } $\begin{array}{c}\text { Tingkat } \\
\text { Sarjana }\end{array}$ & & Hipo & Emp & \\
\hline Tingkat SMA & 17.827 & 127.5 & & Tinggi \\
\hline & 15.690 & 127.5 & & Rendah \\
\hline
\end{tabular}

Berdasarkan hasil penelitian dan analisis perhitungan uji sampel t-test diperoleh hasil dengan nilai $t$ hitung sebesar 3.821 dengan nilai signifikasi sebesar 0,000 ( $p<0,050)$, artinya bahwa hipotesis yang diajukan adaperbedaan penerimaan diri antara ibu dengan tingkat pendidikan sarjana dan ibu dengan tingkat pendidikan SMA yang signifikan. Dengan asumsi bahwa penerimaan ibu dengan tingkat pendidikan sarjana lebih tinggi dibandingkan penerimaan ibu dengan tingkat pendidikan SMA. Berdasarkan hitungan mean hipotetik dan mean empirik yang menunjukkan penerimaan diri ibu yang berpendidikan sarjana berada pada kategori tinggi dengan skor mean hipotetik 127.5 dan mean empiriknya 155.10 serta standart devisiasinya 17.827. sedangkan penerimaan diri ibu yang berpendidikan SMA berada pada kategori rendah dengan skor mean hipotetik 127.5 dan mean empiriknya 138.53 serta standart devisiasinya 15.690 . dari perbedaan mean empirik dan penerimaan diri ibu pada 2 kelompok, diperoleh bahwa ibu yang pendidikan sarjana memiliki penerimaan yang lebih tinggi dibandingkan dengan ibu yang berpendidikan SMA. 


\section{SIMPULAN}

Berdasarkan hasil penelitian menunjukkan ada perbedaan pada penerimaan diri ibu yang berpendidikan sarjana dengan ibu yang berpendidikan SMA, yaitu penerimaan ibu berpendidikan sarjana lebih tinggi dibandingkan penerimaan ibu yang SMA. Hasil ini diketahui dengan melihat $t$ hitung +3.821 dengan nilai signifikasi sebesar 0,000 $(\mathrm{p}<0,050)$.Secara umum hasil penelitian ini menyatakan penerimaan ibu yang berpendidikan sarjana tergolong lebih tinggi hal ini didukung oleh nilai rata-rata empirik diatas nilai rata-rata hipotetik dengan nilai rata-rata empirik 155.10 seangkan nilai rata-rata hipotetiknya sebesar 127.5, adapun nilai SD nya 17.827. sedangkan penerimaan ibu yang berpendidikan SMA tergolong rendah, hal ini dapat dilihat dari rata-rata empiriknya 138.53 dan hasil rata-rata hipotetiknya 127.5, adapun nilai SD ya 15.690 .

Saran untuk ibu, bagi orang tua yang belum dapat menerima kondisi anak, agar dapat mengubah pandangan dan perilaku negatif terhadap anak yang memiliki kebutuhan khusus jika anak berkebutuhan khusus tidak memiliki kemampuan apapun. Orang tua perlu menggali lebih banyak lagi pemahaman tentang anak berkebutuhan khusus melalui buku, majalah atau media elektronik.

Saran untuk ibu lembaga, bagi ibu lembaga dapat mempelajari pola belajar yang baik untuk dapat mengembangkan potensi serta kemampuan para anak didik. Saran untuk peneliti selanjutnya, agar peneliti yang berniat mengangkat tema yang sama, dari hasil penelitian ini nantinya dapat memberi gambaran bahwasanya ada faktor lain yang mempengaruhi penerimaan pada ibu ataupun orang tua untuk penelitian selanjutnya, yaitu dukungan keluarga besar, faktor ekonomi keluarga, latar belakang agama, sikap ahli yang mendiagnosa anak mereka, status perkawinan, sikap masyarakat, usia orang tua, dan saran penunjang.

\section{DAFTAR PUSTAKA}

Amin M.D. 2000. Pengantar Pendidikan Luar Biasa. Jakarta: PT New Aqua Press

Arikunto S, 2006. Prosedur Penelitian Suatu Pendekatan Praktik, Ed Revisi VI, Penerbit PT Rineka Cipta, Jakarta.

Bratanata, S.A. 2001. Pengertian-pengertian Dasar dalam Pendidikan Luar Biasa, Jakarta: Depdikbud.

Delphie, B. 2009. Pembelajaran Anak Berkebutuhan Khusus Dalam Setting Pendidikan Inklusif. Kaltenn: PT. Intan sejati

Dzulfadli, Y. 2007. Cinta Yang Utuh. Mizan: Bandung.

Fuad, I. 2003. Dasar-Dasar Kependidikan, Jakarta: PT. Rineka Cipta Fuad.

Hadi, S. 2004. Metodologi Research. Yogyakarta: Andi Offset.

Haditono, S. R. 2006. Psikologi Perkembangan: Pengantar dalam berbagai Bagiannya. Yogyakarta: Gajah Mada University Press

Hurlock, E. 2004. Psikologi Perkembangan. Jakarta : PT. Gramedia Pustaka

Ihsan, F. 2003, Dasar-dasar Kependidikan, Jakarta : PT. Rineka Cipta Fuad

Johnson,\&. Medinnus. G. 2000. Child Psychology Behavior dan Development Six Edition. United States of America: John Wiley dan Sons, Inc.

Kubler. R. 2008. On Life After Death Revised. USA : Celestial Arts.

Mangungsong, F. 2009. Psikologi dan Pendidikan Anak Berkebutuhan Khusus Jilid I. Jakarta: Lembaga Pengembangan Sarana Pengukuran dan Pendidikan Psikologi (LPSP3), Depok.

2011. Psikologi dan Pendidikan Anak Berkebutuhan Khusus Jilid Ke dua. Jakarta: LPSP3 UI

Mahabati, A. 2009. Penerimaan dan Kesiapan Pola Asuh Ibu Terhadap Anak BerkebutuhanKhusus. Jurnal pendidikan. 5 (2). 
Ade Ari Isnainy \& Laili Alfita., 2016. Perbedaan Coping Stress Penderita Kanker Ditinjau dari Jenis Kelamin di RSUP H. Adam Malik Medan.

Munzayanah. 2000. Tunagrahita. Surakarta: Depdikbud UNS.

Murtadlo. 2006. Peningkatan Kualitas Pembelajaran Siswa Tunagrahita Dalam Membaca Dan Menullis Melalui Pendekatan Kooperatif di Sekolah Luar Biasa. Jurnal. 2 (2)

Novira, F. 2016. Penerimaan Diri Orang Tua yang Memiliki Anak Berkebutuhan Khusus. eJournal Psikologi. 4(4)

Nidar, A. 2008. Dinamika Penerimaan Ibu Terhadap Anak Tuna Grahita. Skripsi. Fakultas Psikologi. Uin Syarif Hidayatullah. Jakarta

Payne, J, \& Jones, D. 1981. Mental Retardation. Columbus: A Bell and Howell Company

Sako, W. R. 2006. Hubungan tingkat pendidikan dan pengetahuan orang tua tunagrahita dengan sikap penerimaan orang tua terhadap anak di SDLB (C) tunagrahita YPPLB Cendrawasih Makassar. Program Studi IlmuKeperawatan Makassar.

Santrock, J.W. 2007. Psikologi Pendidikan (edisi kedua). (Penerj. Tri Wibowo B.S). Jakarta: Kencana.

Singgih D, G. 2003. Psikologi Perkembangan. Jakarta ; BPK Gunung Mulia.

Somantri, S. 2006. Psikologi Anak Luar Biasa, Bandung: Rafika Aditama.

Sugiyono. 2010. Metode Penelitian Kuantitatif Kualitatif \& RND.Bandung: Alfabeta

Wardhani, M.K., Rahayu, M.S., Rosiana, D. 2012. Hubungan Antara "Personal Adjustment" Dengan Penerimaan Terhadap Anak Berkebutuhan Khusus pada Ibu yang Memiliki Anak Berkebutuhan Khusus di RSUD X. Prosiding. Sosial, Ekonomi, Humaniora. Universitas Islam Bandung. 